\title{
Séance de la Chambre médicale
}

\section{Points de l'ordre du jour déjà établis}

- Accueil, communications

- Budgets 2018

- Election complémentaire d'un membre du Comité central et d'un vice-président

- Elections de confirmation des délégués et délégués suppléants à l'Assemblée des délégués

- Enjeux infrastructurels

- Rapport 2017 au sujet des mesures de stabilisation budgétaire

- Modifications des Statuts, du Règlement d'exécution et du Code de déontologie

- Exigences minimales de la révision de la loi sur la protection des données pour la FMH

- Exposé de l'orateur invité

- Tarif ambulatoire

- MARS

- Gestion des admissions

- Problématique «double rôle des médecins»

- Charte qualité

- Listes d'opérations ambulatoires obligatoires: projet pilote

- Informations du Comité central, du Secrétariat général, de l’ISFM et des divisions

- Divers

Tout nouveau point à l'ordre du jour doit être communiqué au secrétariat central (direction[at]fmh.ch) d'ici au 20 septembre 2017. 